\title{
Suicide report indicates shift at WHO
}

See also salon article on page 1112 and at www.cmaj.ca/lookup/doi/10.1503/cmaj.141126, and editorial on page 1043 and at www.cmaj.ca /lookup/doi/10.1503/cmaj.141128

$\mathrm{T}$ he World Health Organization (WHO) has finally spoken out on suicide in its first-ever report on the major killer. Preventing suicide: A global imperative states that suicide claims 800000 lives per year worldwide with three-quarters of those in developing countries, and ranks as the second-leading cause of death for young people age 15 to 29 . The WHO has come under fire for lagging on mental illness, including leaving it off the list of noncommunicable diseases that require the world's attention (cardiovascular diseases, respiratory diseases, diabetes and cancers made the cut), but the report aims to move suicide up on the global agenda.

Dr. Arthur Kleinman of Harvard University, Cambridge, Massachusetts, is among the critics. A psychiatrist and medical anthropologist who has studied mental illness in low- and middleincome countries for more than 40 years, he famously called global mental health a "failure of humanity" in an editorial in The Lancet five years ago. But now he says the ground has shifted.

"Something has happened in the last couple of years that has pushed the WHO to a degree of support for the mental health area that is unique in my experience of the WHO," he told CMAJ. There's a consensus he says, "not only that it's time to act, but ...

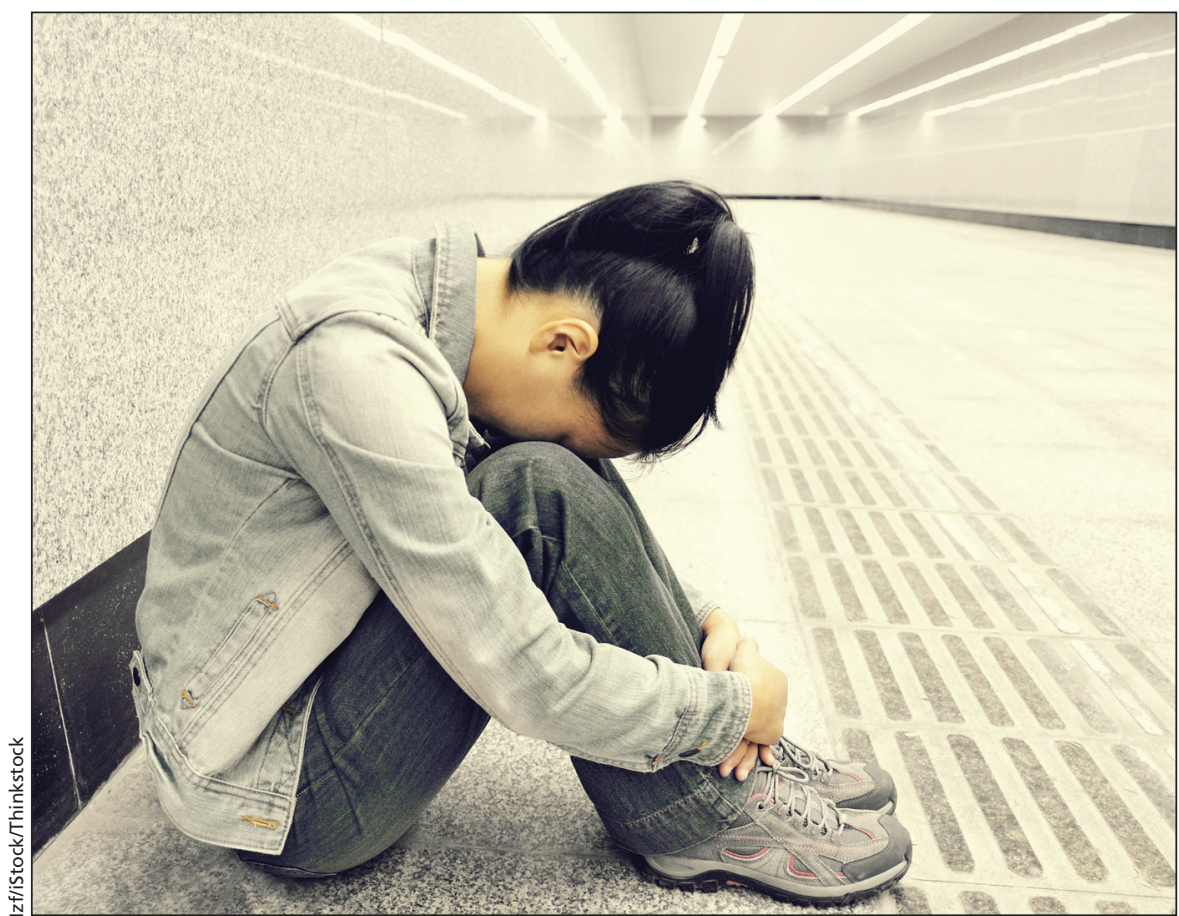

Suicide claims $\mathbf{8 0 0} 000$ lives annually; three-quarters of those are in developing countries.

batting a high suicide rate. Focusing on methods of suicide, China lowered the ingestion of pesticides, which young women in rural areas often use in an attempt to end their lives. The government banned certain pesticides, diluted and decreased the toxicity of others, and controlled their sale. The Chinese government has also piloted restricting the sale of charcoal, which is deliberately

\section{The World Medical Association is appealling to physicians to work with their governments on national suicide prevention strategies.}

there's [also] recognition that there are ways of acting, there are concrete, implementable interventions, and it's unconscionable that these are not being used."

He points to China as a country that has put increasing resources into com- burned for its toxic carbon monoxide. Supermarket chains in Hong Kong took charcoal packs off open shelves in stores as part of a controlled trial, though they have since reverted to open sales. China's suicide rate dropped by about $60 \%$ between 2000 and 2012, from 19 per
100000 to about 8 per 100000 , according to the WHO. Canada's suicide rate also fell during that period, from 11 per 100000 to about 10 per 100000 .

Speaking at the launch of the report on Sept. 4 at WHO headquarters in Geneva, Dr. Margaret Mungherera, a psychiatrist from Uganda and president of the World Medical Association, said her organization would appeal to physicians to work with their governments on national suicide prevention strategies. Only 28 countries currently have such plans.

WHO is calling for countries to develop national plans with sustained funding, but many lack the resources. However, Kleinman is hopeful. "The World Bank and the WHO are in conversations about this," he says. "You might see something." - Miriam Shuchman, Toronto, Ont.

CMAJ 2014. DOI:10.1503/cmaj.109-4897 